\title{
Cultura urbana, linguagem visual e publicidade nos tempos do Rio Moderno
}

\author{
Laura Martini Bedran*
}

\section{Resumo}

Esse artigo trata sob um viés histórico, da cidade do Rio de Janeiro que, no início do século XX, ao ser remodelada como cidade capital, direcionou não somente uma nova arquitetura de fluxos, como também, e principalmente, gerou novos comportamentos sob a regência do urbano. Nesse contexto, a pesquisa pretende demonstrar que as aplicações da arte e da indústria gráfica atuaram como mediadoras entre as classes urbanas e que, entre as variadas expressões da cultura impressa, a publicidade brasileira surgiu com desenvoltura e fez uso das características desse novo ambiente com o desenvolvimento de uma linguagem dinâmica e inovadora.

Palavras-chave: Cidade moderna. Visualidade urbana. Rio de Janeiro. Cultura impressa. Publicidade.

\section{Urban visuality, print culture and expansion of advertising in modern times of Rio}

\section{Abstract}

This article discusses over a historic point of view the city of Rio de Janeiro in the early twentieth century. To be recast as the capital city, it was not only directed to a new flowing architecture, as well as, and mainly, it generated new models urban behaviors. In this context, the research intends to demonstrate the applications of the art and the graphical industry had acted as mediating between the urban classes and that among the varied expressions of print culture, where the Brazilian advertising appears with nimbleness and makes use of the characteristics of this new environment to develop a dynamic and innovative language.

Keywords: Modern city. Urban visuality. Rio de Janeiro. Print culture. Advertising.

* Professora Adjunta do Departamento de Comunicação Social do Instituto de Artes e Comunicação Social da Universidade Federal Fluminense (UFF). NiteróiRJ, Brasil. É doutora em Comunicação e mestre em Artes Visuais. Coordena o projeto de pesquisa "Mídia e Cidade: imagens de publicidade no cotidiano urbano". E-mail: laura.bedran@yahoo.com.br 


\section{La visualidad urbana, la cultura impresa y la expansión de la publicidad en los tiempos del Rio Moderno}

\section{Resumen}

En este artículo se busca dar a conocer por el sesgo histórico el Río de Janeiro que en el siglo XX, a una refundición de la ciudad capital dirigido no sólo una nueva arquitectura de los flujos, pero también, y principalmente generado nuevos comportamientos inspirado en la regencia del urban. En este contexto, la investigación pretende demostrar las aplicaciones del arte y la industria de la impresión actuaron como mediadores entre las clases urbanas, donde el lenguaje de la publicidad viene con vigor y hace uso de las características de este nuevo entorno para desarrollar un lenguaje innovador y dinâmico.

Palabras clave: Ciudad moderna. Visualidad urbana. Río de Janeiro. La cultura impresa. La publicidad.

\section{Introdução}

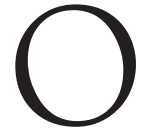

fenômeno de urbanização que, em determinados aspectos e costumes, aproximou diferentes nações, no Brasil, efetivamente, se fará notar somente no início do século 20 com a reorganização da cidade do Rio de Janeiro inspirada pelo modelo europeu de cidade moderna. Configurada à luz das novas concepções de civilidade e progresso, a cidade remodelada direcionou, não somente uma nova arquitetura de fluxos atendendo às necessidades de locomoção do público e ampliação da indústria e do comércio, como também, e principalmente, gerou novos comportamentos modelados sob a regência do urbano. As aplicações da arte e da indústria gráfica atuaram como mediadoras entre as classes urbanas que convergiram para si uma linguagem tão ágil quanto o novo cotidiano experimentado. Nesse contexto, sobre a cultura impressa da época, a publicidade brasileira surgiu com desenvoltura e fez uso das características desse novo ambiente para desenvolver uma linguagem dinâmica e inovadora.

Este artigo resulta de parte de um estudo sobre visualidade urbana e comunicação no qual os espaços da cidade são compreendidos como áreas de consumo com possibilidades de novas materialidades e dimensões. Nesta proposta, procura-se demonstrar por meio do viés histórico, que as transformações urbanas do início do século 20, na cidade do Rio de Janeiro, promoveram uma nova 
imagem da cidade conjugada com a experiência sensorial que a cidade passou a promover.

Como metodologia para investigação da proposta, utilizamos uma pesquisa bibliográfica articulada com uma pesquisa empírica, realizada junto aos acervos iconográficos do Museu da Imagem e do Som e da Fundação Biblioteca Nacional.

\section{Rio Moderno: reflexos na imagem da cidade}

O espaço público moderno como uma nova forma de interação social foi configurado no Rio de Janeiro nos primeiros anos de 1900, com a intenção de transformar a maior e mais importante cidade do país em uma cidade modelo. A capital federal remodelada à moda parisiense introduziu novos hábitos na cidade que, de certo modo, passou a promover a convivência entre diferentes mundos que caracterizam a multiplicidade urbana. Sentados às mesas dos cafés que se espalhavam pelas calçadas da nova avenida, grupos conversavam ou simplesmente instigavam-se a observar a vivacidade da rua moderna carioca. O comércio no centro do Rio de Janeiro passou a ser, notavelmente, cenário da vida elegante da cidade.

A esta visualidade, soma-se a energia elétrica que a cidade passou a exibir, vaidosa de seus prazeres. Já na primeira década do século 20, a substituição dos lampiões a gás gradativamente iluminou ruas, vitrines e casas das classes média e alta cariocas (CENTRO DE MEMÓRIA DA ELETRICIDADE NO BRASIL, 2001). As melhoras no fornecimento de energia foram fundamentais para impulsionar a indústria do entretenimento no Rio de Janeiro, com clubes e associações promovendo eventos esportivos e festas. (ARAÚJO, 1993, p.336). Também as casas de cinema se beneficiaram com as melhorias da iluminação pública. Apesar do encantamento proporcionado desde que surgiu na cidade, ao final do século 19, somente com o fornecimento de energia adequado às exigências da nova invenção, a indústria cinematográfica pode avançar com a inauguração de diversas salas de exibição (MIRANDA, 1985, p.92).

Movidos à tração elétrica em diferentes versões, desde os mais populares aos mais sofisticados, com luxuosos forros sobre os 
assentos, os bondes se modernizaram. Cruzando a cidade, unindo bairros e estreitando caminhos intensificaram o movimento cotidiano do Rio de Janeiro. $\mathrm{O}$ automóvel também se tornou um símbolo das mudanças que o novo século trazia ao Brasil moderno; com as melhorias promovidas após a urbanização e pavimentação das ruas, o aumento do fluxo de veículos logo forçou a elaboração de leis de regulamentação do seu uso.

A fruição do espaço urbano estendia-se ao progresso que estava nas ruas movimentadas pelo comércio, pela elegância dos pedestres, pelos bondes e automóveis em trânsito. Nas ruas cariocas vislumbravam-se as novidades:

No burburinho das ruas, homens trajando paletós de casimira clara e usando chapéu de palha, acompanhados de senhoras finamente vestidas com toaletes de nítida inspiração parisiense, desfrutavam os tempos eufóricos da Belle Èpoque. Deslumbravam-se diante do novo aparato que incluía equipamentos e objetos de consumo identificados com as marcas do progresso e da modernidade. Telefones, automóveis, elevadores, cinematógrafos, fonógrafos, bondes, iluminação elétrica, vacinas, logo se converteram em motivo de regozijo e até mesmo de reverência solene (SCHAPOCHNIK, 2004, p.440).

Para além da praticidade e conforto possibilitados pela locomoção nos novos meios de transporte dentro da cidade, a fruição de uma nova paisagem que se configurou ao olhar, proporcionou subjetividades até então não experimentadas. Uma imagem "desrealizada" (SUSSEKIND, 2006, p.50), transformada de seu estado natural, passou a intensificar o cotidiano urbano produzindo no público uma nova percepção, ao mesmo tempo em que também ela era capaz de oferecer um novo repertório de referências visuais.

Crary (2004) classifica essa experiência visual nova, percebida pelas mudanças alavancadas pelos processos de industrialização e urbanização, como uma modernização do olhar que irá declinar o padrão clássico de observação. Para o autor, as mudanças percebidas nos campos científicos, como a que relaciona a experiência visual atrelada à experiência sensorial, acarretaram novas condições de aplicabilidade de técnicas de manipulação e estímulo.

Uma vez determinado o fato de que a verdade empírica da visão situava-se no corpo, os sentidos - e a visão em particular - puderam ser anexados e 
controlados por técnicas externas de manipulação e estimulação. Essa foi a conquista histórica da ciência da psicofísica nos meados do século XIX - sobretudo o trabalho do cientista-filósofo Gustav Fechner - que tornou a sensação mensurável e firmou a percepção humana no domínio do quantificável e do abstrato. A visão, assim, tornou-se compatível com muitos outros processos da modernização (CRARY, 2004, p.68).

Sobre as modernizações impostas ao olhar nas paisagens das cidades modernas, Nelson Brissac Peixoto (2003, p.97-98) também faz referências à formação de um novo observador:

Surge um 'observador ambulante', formado pela convergência de novos espaços urbanos, tecnologias e imagens. Deixa de existir a própria possibilidade de uma postura contemplativa. Não há mais um acesso único a um objeto, a visão é sempre múltipla, adjacente, sobrepondo outros objetos. Um mundo em que tudo está em circulação. [...].

A pluralidade de vistas foi condição para a formação de um observador competente para assumir as vastas quantidades de imagens e informações que começavam a ser postas em circulação no século XIX.

Se a cidade moderna insere o indivíduo em um turbilhão de novidades, fazendo do seu cotidiano uma experiência que perpassa o sensorial, é preciso que ela invente também uma maneira de dialogar com esse indivíduo nessas mesmas condições instauradas pelo urbano.

\section{A cultura impressa e o desenvolvimento da publicidade}

Aos olhos da cidade moderna, a multidão anônima foi transformada em público, e convergiu para si uma linguagem tão ágil e estimulante quanto o seu cotidiano. A indústria gráfica, com seus aprimoramentos técnicos, exerceu um papel fundamental na inter relação entre as classes urbanas. $\mathrm{O}$ desenvolvimento da cultura impressa, acrescido da reprodução de imagens, tornou-se um forte diferencial na linguagem visual do século 20.

Mesmo a fotografia, que já circulava desde o século 19 com relativa naturalidade nas famílias brasileiras sob a forma de retratos, com as inovações técnicas do novo século passa a incorporar qualidades diferentes de representação. A possibilidade técnica de conversão da imagem fotográfica de tom contínuo, em imagem 
impressa a meio tom por meio dos processos gráficos em evolução, promoveu uma grande popularização da fotografia disseminada sobre os meios impressos da época. E, principalmente, com essa possibilidade, observa-se uma ampliação dos usos da fotografia até então utilizados. Mais claramente, quando em 1900 as primeiras fotos foram impressas na Revista da Semana por meio do processo gráfico denominado fotogravura, elas absorveram para si novas características como efemeridade e cotidianidade, atributos antes relacionados aos jornais e revistas, diminuindo assim o seu caráter perene, um traço marcante do uso anterior relacionado aos retratos de família (SUSSEKIND, 2006, p.72).

Os cartões postais ilustram outra aplicabilidade da fotografia como linguagem visual. Se por um lado as imagens fotográficas impressas sobre os pequenos cartões ofereciam a redução de uma realidade, por outro lado ampliavam o conhecimento sobre um determinado tema, incitando desejos e o imaginário ao se mostrarem como "um convite à viagem, uma prenda delicada àqueles que estão distantes; imagens cuidadosamente escolhidas servem de moldura a juras de amor, reiteram plasticamente laços de amizade, perplexidade e encantamento" (SCHAPOCHNIK, 2004, p.424).

E não apenas paisagens eram retratadas. Nos postais, estava também a elite, o povo, os artistas, o comércio, os políticos e o corpo feminino desnudo - uma ousadia para a época. Os postais instigaram a população a colecioná-los. Muitas vezes, autografados ou não, traduziam na prática uma espécie de grande álbum, contendo um vasto repertório de imagens disseminadas pelas inovações e técnicas do novo século. A imagem da cidade moderna e civilizada impõe-se traduzida sobre os postais:

Uma outra série de postais se integrava num tempo que poderia ser denominado de futuro do presente, isto é, configuravam-se em imagens que deveriam ser consumidas como o novo cenário da cidade remodelada. Não por acaso, muitas das fotos registradas por Augusto Malta, fotógrafo oficial da administração Pereira Passos, foram convertidas em cartões-postais que projetavam e potencializavam simbolicamente o desejo de fixar o perfil modernizado do Rio de Janeiro e de seus habitantes (SCHAPOCHNIK, 2004, p.443).

Apesar disso, curiosamente, muitas dessas imagens tentavam resgatar, já naquela época, ruínas, com registros fotográficos de 
prédios antigos, casarios sem futuro e trabalhadores informais, como ambulantes com seus pés descalços "salvando dos escombros uma realidade que se esvaía sob o tempo do presente do pretérito [...] que atestava a irreversibilidade do processo vivido na cidade" (SCHAPOCHNIK, 2004, p.441).

A irreversibilidade da realidade moderna transpassada mudou gradativamente a imagem da cidade onde uma nova visualidade era demarcada por meio de novos sinais refletidos. Com cidade e sociedade urbana em expansão, a cultura de consumo passou a ocupar lugar de destaque no cotidiano. As casas comerciais com suas entradas abarrotadas de mercadorias em exposição, características do início do século, aos poucos perdem a cena para as vitrines ornamentadas e produzidas, exibidoras de produtos e marcas que começavam a se impor no mercado em expansão. A potencialização da imagem é assistida sobre diferentes modalidades do cotidiano urbano.

Quando as modernizações da indústria gráfica, na virada do século, no Rio de Janeiro, remodelaram a imprensa tradicional, o mercado editorial foi acrescido das revistas semanais, mudando o tom da imprensa no país. Os diversos públicos que, de alguma maneira, foram ensaiados nos vários periódicos que circularam ao longo do século anterior, vêm à tona com maior clareza na grande diversidade de revistas literárias, de entretenimento, femininas, ou infantis:

Se os jornais marcaram o nosso período anterior, nascidos muitas vezes da luta política, saindo e se multiplicando, fechando e sendo substituídos, criando esse clima de participação que foram as últimas décadas abolicionista e republicana, 1900 muda a tônica da imprensa para as revistas. Semanais, ilustradas. E nelas se vê uma nova atmosfera. Agora é o instante da crônica social, da charge e do soneto. Os homens do governo não são mais atacados, são alvo de sátira; os fatos do dia não se traduzem em notícia, mas vêm no leve comentário; e com as rimas, que tomam largo espaço, não há um menor fascínio pela Academia. Tempo de Bilac, das fotos de senhorinhas, dos ecos parisienses. Sustentando isso tudo, principia uma propaganda regular. (RAMOS; MACONDES, 1995, p.21-22).

Assim como as revistas e os jornais ganharam cotidianidade com a crônica social, a fotografia impressa, a charge e o humor, 
também a atividade da publicidade, a partir desse momento, passaram a uma produção intensificada por uma linguagem muito mais interativa com o leitor. A redação por rimas, a ilustração a cores e o planejamento do anúncio de acordo com o seu suporte, passaram a integrar a comunicação publicitária que começou a se profissionalizar com o trabalho de artistas gráficos e poetas.

Conhecidos do público no século 19, os anúncios que se expressavam em um tom pessoal e reproduziam uma linguagem estritamente informativa como "aviso", "atenção" ou "vendo uma casa..." já não atendiam à nova cidade. A propaganda que se espalhou sobre os vários impressos do novo século apropriou-se da modernidade vivenciada e introduziu uma nova técnica de redação, com uma linguagem que passou a propor diálogos criativos com o público. Sussekind (2006) analisa que o tom pessoal encontrado nos anúncios publicados no século 19 não expressava o novo comportamento vivenciado nas cidades que cresceram:

Há uma intimidade que parece indicar da parte do anunciante ser ele capaz de delimitar com alguma precisão aqueles com quem falaria no seu aviso. Situação que se transborda radicalmente quando aparecem os reclames impessoais, as firmas encarregadas de veicular anúncios, os primeiros profissionais de propaganda. Aí já não é mais o próprio interessado quem redige o seu anúncio. E nem o público, agora difuso, dos jornais, panfletos, e cartazes citadinos permitiria propagandas ao pé do ouvido. Assiste-se, assim, aos primeiros passos de uma 'indústria do reclame' (SUSSEKIND, 2006, p.61).

A sedução das mensagens foi aperfeiçoada por uma linguagem criativa, oferecida com muita habilidade por meio da redação de grandes escritores nacionais. Se com a imprensa jornalística muitos homens de letras do país já haviam encontrado certa "notoriedade, em primeiro lugar; e um pouco de dinheiro, se possível” (SODRÉ, 1999, p.292), o aumento das mercadorias em circulação impulsionou o ofício que, mais claramente, não negava o seu caráter mercantil:

Muitos dos homens de letras mais conhecidos do Brasil de inícios do século XX não hesitaram em aceitar o papel de homens-sanduíche também. Bilac, Emílio de Meneses, Hermes Fontes, Bastos Tigre são alguns dos que mergulharam de cabeça na redação de quadrinhas e sonetos de propaganda. 
O caso de Bastos Tigre, dentre eles, é especialmente significativo. Era dos anúncios que tirava, muitas vezes, seu sustento, chegando inclusive a montar um escritório - Publicidade Bastos Tigre - em que atendia aos mais diversos anunciantes: Confeitaria Colombo, Cafiaspirina Bayer, Cigarros York, Magazine Notre Dame; Drogaria V. Silva, Cervejaria Fidalga. (SUSSEKIND, 2006, p.63).

Bastos Tigre teve uma produção intensa que atravessou gerações. São de sua autoria o objetivo slogan "Se é Bayer é bom”, e também os tão famosos "versos-reclame para o Rhum Creosotado: 'Veja ilustre passageiro / O belo tipo faceiro / Que o senhor tem ao seu lado / No entanto, acredite / quase morreu de bronquite: salvou-o o Rhum Creosotado"”. (SUSSEKIND, 2006, p.63).

A linguagem lúdica que a publicidade da época passa a apresentar é notada especialmente neste anúncio do Rhum Creosotado, veiculado em cartazes fixados dentro dos bondes, em que o título põe em interação personagens fictícias com o leitor. As referências acumuladas na experiência do público começam a compor o repertório criativo dos reclames.

Já nessa época, a publicidade caracterizou-se como uma linguagem de apropriação de espaços, em que a cidade é o suporte. Não à toa, os bondes foram apropriados pelos cartazes de propaganda. Inseridos no cotidiano urbano carioca, os bondes elétricos uniam o centro ao subúrbio e aos bairros à beira mar. Transportavam seus passageiros não somente ao trabalho, mas aos estudos, às compras, ao lazer. Os diferentes tipos de carros atendiam as diferentes classes sociais. A condição inovadora de reunir estranhos de forma tão próxima muitas vezes extrapolava os domínios da privacidade e proporcionava momentos de descontração. Os bondes travaram com o público carioca uma intensa relação, que superou os conflitos causados pelos constantes atrasos no decorrer dos anos em que circularam. Incitou personagens que povoaram o imaginário carioca, como o motorneiro, o condutor, o fiscal, inspirando composições e expressões populares como a máxima: "tudo na vida é passageiro menos o condutor e o motorneiro". E, tendo a linguagem da publicidade uma das características que a fazem eficaz - o alinhamento com as questões da atualidade, com o objetivo de trazer para o cotidiano o produto/marca, colocando-o 
próximo ao consumidor -, nada mais propício do que o uso do bonde como suporte da mensagem publicitária, devido à sua cotidiana presença na vida do carioca.

Os bondes comportavam dois tipos de anúncios, os fixados do lado de fora e os fixados nas paredes internas. Os cartazes que eram fixados nas paredes internas produziam uma atividade sensorial interessante e inédita nos usuários. Os versos do famoso Rhum Creosotado, já comentados, brincavam com o "ilustre passageiro" e o imaginário cavalheiro ao seu lado. Os relatos das lembranças da infância de Zélia Gattai e suas irmãs, recolhidos por Sevcenko (2004), atestam a grande popularidade que os anúncios fixados nos bondes adquiriam. Ela lembra com clareza que, junto a suas irmãs, durante a viagem, participava do jogo interativo proposto pela comunicação dos anúncios, que era capaz de encurtar as distâncias percorridas e distrair da canseira de se viajar de pé. Os versos-reclame eram lidos e repetidos pelas crianças em brincadeiras em voz alta e causavam admiração e graça também nos passageiros. $\mathrm{O}$ autor comenta que o ambiente interno do bonde criava, muitas vezes, o espaço propício à observação e distração do olhar. $\mathrm{O}$ isolamento do indivíduo em busca de sua privacidade em meio ao espaço público, absorto em seus pensamentos, era o campo explorado pela comunicação:

Isolar-se na privacidade significava em geral absorver-se no silêncio das próprias reflexões ou, na falta delas, do mero tédio. Era dessa disponibilidade da imaginação que a publicidade carecia, captando-a com truques sensoriais, cativando-a pelas promessas e seduzindo-a pelo desejo (SEVCENKO, 2004, p.552).

Por sua vez, os anúncios em exposição na parte externa dos bondes produziam a dinâmica da leitura em movimento e carregavam as mensagens de um canto a outro da cidade, repetidas vezes, fixando-as na memória visual dos leitores.

Os anúncios ilustrados eram, em sua maioria, desenhados pelos profissionais das artes gráficas da imprensa carioca, como Julião Machado, Raul Pederneiras, K. Lixto e J. Carlos. Como jornalistas caricaturistas, afinados com o noticiário do país, trouxeram à linguagem dos anúncios uma associação inusitada entre os mais célebres homens da política da época e esdrúxulas mercadorias: 
Afonso Pena, Barão do Rio Branco, Pinheiro Machado são nomes diretamente associados a produtos, em charges e diálogos que dão quase testemunhos. A caricatura é uma dominante, frisa o clima de circunstância, empresta à propaganda uma inflexão bem-humorada (RAMOS; MARCONDES, p.26).

Segundo Ramos e Marcondes (1995, p.27), é bastante liberal o uso da imagem dos políticos mais conhecidos em diálogos em "tom de glosa", com humor, trazendo para a linguagem uma irreverência alegre, e até mesmo, ingênua:

Imagine-se o presidente da República, visto no traço de um desenhista popular, fazendo as referências mais elogiosas aos artigos de uma loja qualquer. Ou posando com seus ministros, diante de um grande bazar, todos vestidos de quimono, com chapéu de bico e cheios de embrulhos, dizendo que acabaram de fazer compras fabulosas. É isso que acontece com Afonso Pena, em 1909, e vem nas páginas de Fon-Fon. [...]

Há muitos outros exemplos que seguem de 1909 até por volta de 1918, utilizando as personalidades mais em voga de cada fase. É Rodrigues Alves, é Campos Sales. Falando neste, há uma quadrinha famosa, atribuída a Olavo Bilac, e que Pedro Nunes afirma ter o poeta ganho $100 \$ 000$ para escrever: 'Aviso a quem é fumante / Tanto o Príncipe de Gales / Como o Dr. Campos Sales / Usa Fósforos Brilhante'.

Decerto que, no Brasil, de início a ilustração apropriada para fins comerciais aproximou-se com mais afinidade dos desenhistas da imprensa que já vinham, há alguns anos, desenvolvendo uma linguagem com o mercado da imagem impressa. Mas alguns esboços mostram que certos acadêmicos do início do século também foram solicitados e investiram nesse campo. $\mathrm{O}$ acervo iconográfico da Fundação Biblioteca Nacional do Rio de Janeiro dispõe de alguns registros de trabalhos gráficos realizados nessa área. Entre eles, destaca-se o estudo de Henrique Bernardelli (1909), em técnica de aquarela sobre papel, para reprodução do convite-programa de inauguração do Teatro Municipal do Rio de Janeiro. Outro trabalho representante da afinidade de artistas com a cultura impressa da época é de autoria de Eliseu Visconti (1920). O artista apresenta, em técnica de aquarela e guache sobre papel, um cartaz de propaganda de cerveja para a Companhia Antarctica do Rio de Janeiro. Os dois artistas, tendo imigrado para o Brasil ainda no 
século 19, são considerados grandes pintores nacionais. Atuaram como mestres da Escola Nacional de Belas Artes e alcançaram o reconhecido valor por suas obras no período em que viveram. Bernardelli, entre outras obras, assina os painéis decorativos do Museu Nacional de Belas Artes, Teatro Municipal do Rio de Janeiro e Biblioteca Nacional; e Visconti, além dos seus iluminados retratos de paisagens com influência impressionista, é considerado um precursor do design brasileiro, por seus desenhos aplicados aos selos, papéis de parede, cartazes e luminárias.

Talvez os estudos apresentados pelos dois artistas consagrados na época não tenham passado de projetos, e isso denota, de alguma maneira, dificuldades no período estudado em relação ao conceito de arte e às manifestações populares da imagem impressa. Enquanto em alguns países da Europa, desde o século 19, o aperfeiçoamento da litografia promoveu um estreitamento entre a arte aplicada para fins comerciais e os cartazes de propaganda assinados por artistas consagrados como Toulouse Lautrec, nota-se que, no Brasil, principalmente as limitações da indústria gráfica, associadas a uma economia ainda em formação, retardaram o desenvolvimento da imagem comercial impressa como imagem artística. Neste aspecto, as capas das revistas que circularam intensamente nas duas primeiras décadas - pioneiramente, Revista da Semana, em 1900, seguida por O malho, Fon-Fon e Careta, entre outras - foram um suporte economicamente viável para a produção de uma imagem-arte aplicada às técnicas de reprodução com capas ilustradas, cuidadosamente impressas, exigindo o minucioso trabalho de seleção de cores dos litógrafos e impulsionando o desenvolvimento da linguagem gráfica no Brasil.

Nessa época, os cartazes impressos, faziam uso, em sua maioria, do desenho como ilustração do anúncio e, raramente, a composição incluía a fotografia por meio do uso de clichês. As composições mais bem produzidas, desenhadas com apuro para impressões litográficas coloridas, limitavam-se a uma pequena tiragem, devido ao alto custo exigido e ao longo tempo despendido. Quando reproduzidos graficamente em altas tiragens, eram impressos ainda sobre uma folha apenas, porém, muitas vezes, já eram exibidos colados lado a lado, com o objetivo de intensificar a mensagem 
por meio da repetição. A cidade, em crescimento urbano, repleta de tapumes, estava propícia ao lambe-lambe, como era chamado esse tipo de cartaz.

O conceito de publicidade - o que torna público - urge na dimensão da necessidade de expansão de mercadorias, modos, saberes, cultura, entretenimento. Ele se faz presente sobre os mais variados suportes e das mais diversas maneiras. A propaganda que adentra o século 20 por meio dos versos-reclame e do traço jocoso dos caricaturistas nos jornais e revistas torna-se muito mais ampla, pois introduz uma linguagem que busca dialogar com os suportes, criando espaços de propaganda. O próprio conceito de embalagem adquire novas dimensões; os produtos, que tiveram uma expressiva expansão, com o novo mercado demandado das cidades, passam a exibir uma embalagem que deixa de ser apenas um invólucro da mercadoria para assumir o papel de propaganda do produto, com ilustrações e desenhos de letras com maior apelo persuasivo. Alguns produtos também se tornam suportes para a propaganda de terceiros, como no caso de baralhos e caixas de fósforos:

Ganhar dinheiro fazendo reclame era uma idéia definitivamente instalada na virada do século, assim como desenvolver embalagens atraentes, conforme se depreende dos registros de patentes de invenções da época. Pedia-se o privilégio de invenção para utilizar o Biombo Anunciador, um aparelho para fixação de anúncios. Ainda no período, há vários pedidos de registro referentes a embalagens para cigarros, fósforos e charutos, como também relativos a invenção de processos para fazer propaganda em baralhos, caixas de fósforos e até através de um sistema de anúncios ambulantes. Não propriamente ambulantes, mas certamente móveis seriam os reclames colocados nos bondes (CAMARGO, 2003, p.66).

A indústria farmacêutica também teve uma intensa atuação na produção de anúncios. São muitos os remédios anunciados para a cura de diversos males, o que, segundo Sevcenko (2004), a acentuada ênfase dada aos remédios, com tantos anúncios divulgados, pode ocorrer devido às novas condições de vida, muito mais aceleradas, concorridas, individualistas; situações indicadoras de indisposições somatizadas que os laboratórios logo se dispuseram a suprir.

Até a segunda década, as gráficas, que eram chamadas de "casas de obras", confeccionavam de tudo - jornais, revistas, folhetos, 
rótulos, etiquetas, cartazes - e propagavam o ofício como escolas, formando profissionais (CAMARGO, 2003). A propaganda passou a ser uma linguagem cotidiana e se distribuiu pelos mais variados suportes, consolidando a sociedade de consumo que emergiu como uma das urbanidades geradas pela cidade moderna. A cidade efervescente urgia por reclames de toda a forma. A rua, com seu intenso fluxo e circulação de pessoas, ofereceu o ambiente propício à linguagem da publicidade: saindo dos jornais e revistas, espelhou o urbano por sobre os muros, tapumes, vitrines, bondes, placas protetoras de canteiros e, também, homens-sanduíche.

Recorremos a João do Rio, que especialmente por meio de uma de suas crônicas publicadas em 1911, "O reclamo moderno" (RIO, 2005, p. 61-64), retrata com clareza o quanto a nova cidade inflamou os arautos de todo e qualquer feito ou gente. $\mathrm{O}$ autor ainda lança uma visão ácida aos líricos que se entregaram a este ofício:

O reclamo! É preciso dar na vista, chamar a atenção. Foi-se o tempo da frase: 'A boa qualidade impõe-se'. Não há boas qualidades: há reclamo, a concorrência; a intensidade reclamo do rumor. Todos nós estamos à porta de uma barraca de feira, ganindo a excelência dos nossos produtos. Liricamente magoado, ouvira durante meia hora a palavra entusiasmada do poeta Pedreira, que se fizera agente de anúncios e cheio de dinheiro desprezava agora os alexandrinos e os outros poetas. [...]

$\mathrm{O}$ reclamo é o rochedo a que se agarram os salvados do desastre. $\mathrm{O}$ reclamo gritado, estridente, reclamo que é às vezes mentira, que é às vezes inconveniência, que chega a ser calúnia, mas que faz aparecer na mente alheia, com a brutalidade de um prego entre os olhos, o nosso nome, o nosso feito, a nossa ação individual.

Nesta crônica, João do Rio expõe muitas possibilidades negativas que se podem atribuir à força da linguagem da publicidade - o seu caráter invasivo e inconveniente; o engodo, a mentira - e de maneira astuta vai além dos males atribuídos restritamente ao produto ou serviço em si, enxergando a abrangência da linguagem da publicidade nos primórdios da sociedade do espetáculo, nos anos 1910.

Quando, ao final da década de 20, Paulo Mendes de Almeida publica um livro de poesias intitulado Cartazes e ilustra a capa com uma composição de logotipos das marcas mais expressivas 
da época, fica flagrante a inserção da linguagem da publicidade no cotidiano urbano. No prefácio, o autor sente a necessidade de explicar ao seu público a razão da transgressão de imagens em que une a poesia e reclames:

Pois é...

Ora vejam só que coisa horrível! Anúncios na capa de um livro de versos! Pois é... Não é horrível, não. Versos publicados, o que são senão propaganda das emoções sentidas? Cartazes, cartazes...

Haverá quem não goste de olhar os cartazes? É lindo! Os nomes dos produtos cantados pelo alto-falante das cores! E nas cidades modernas, o conjunto de todas essas vozes, de todos esses gritos de fé, na sua harmonia bárbara, bárbara como o canto dos motores de 200 H.P., é um hino vibrante cantado ao progresso pelo frontispício dos prédios!

A época é dos cartazes. Vencerá quem tiver cartazes mais bonitos. Chamo os meus versos de 'cartazes' [...]. (ALMEIDA, 1928, p. 3).

E no poema que dá nome ao livro, expressa o vigor da linguagem publicitária que invadiu as ruas nas primeiras décadas do século, com anúncios em busca de donos que captassem suas mensagens lançadas pela cidade:

O REI DOS AUTOMÓVEIS!

O MELHOR CHOCOLATE!

A PRIMEIRA ÁGUA DE MESA!

HOJE! HOJE! O GRANDE FILME 'ALI-BABÁ'!

E no turbilhão da grande avenida,

perdido entre a multidão,

o ouvido ressoante do ruído intenso,

vendo o apaga-e-acende dos cartazes luminosos,

fico a pensar na inutilidade do reclame...

Se há tantos anos,

sem o menor resultado,

eu trago aceso, em grandes letras luminosas,

este cartaz berrante, nos meus olhos:

Mulheres! Atenção!

Peçam prospectos!

Eu vos dou quase grátis

O primeiro, o melhor dos corações! (ALMEIDA, 1928, p. 5). 


\section{Considerações finais}

Durante as primeiras décadas do século 20, a cidade do Rio de Janeiro estendeu urbanidades como cidade capital, refletora da modernidade para o país. Entre as urbanidades geradas, uma nova linguagem visual se destacou e se desenvolveu sobre diferentes suportes. Quer na comercialização de produtos, quer na divulgação de eventos, a linguagem publicitária explorou a visualidade de cidade moderna como suporte, inserindo informações que buscaram por meio de uma peculiar sedução, diálogos com o público. Sobre jornais e revistas, colados sobre tapumes e muros; pintados sobre fachadas de lojas e prédios; ou circulando sobre tabuletas, homenssanduíche e bondes - os anúncios divulgaram o lazer, promoveram o consumo e espelharam a visualidade da cidade moderna que, para além de seus domínios, expandiu subjetividades.

\section{Referências}

ALMEIDA, Paulo Mendes de. Cartazes. São Paulo: Livraria Liberdade, 1928.

ARAÚJO, Rosa Maria Barboza de. A vocação do prazer. A cidade e a família no Rio de Janeiro republicano. Rio de Janeiro: Rocco, 1993.

BERNARDELLI, Henrique. Esboço para programa. 1909 - 1 original colorido de pintura sobre papel - Obras Raras e Iconografia / Fundação Biblioteca Nacional.

CAMARGO, Mário de. Gráfica. Arte e indústria no Brasil, 180 anos de história. São Paulo: Edusc; Bandeirantes, 2003.

CENTRO DE MEMÓRIA DA ELETRICIDADE NO BRASIL. A vida cotidiana no Brasil moderno. A energia elétrica e a sociedade brasileira. Rio de Janeiro, 2001.

CRARY, Jonathan. A visão que se desprende: Manet e o observador atento no fim do século XIX. In: CHARNEY, L.; SCWARTZ, V. (Org.). O cinema e a invenção da vida moderna. São Paulo: Cosac Naify, 2004. cap. 2, p. 67-94.

MIRANDA, Orlando P. A era dos bacharéis. $1^{a}$ parte. São Paulo: Abril Cultural, 1985. 
PEIXOTO, Nelson Brissac. Paisagens urbanas. São Paulo: Senac, 2003.

RAMOS, Ricardo; MARCONDES, Pyr. 200 Anos de Propaganda no Brasil. Do reclame ao cyber-anúncio. São Paulo: Meio \& Mensagem, 1995.

RIO, João do. O reclamo moderno. In: GOMES, Renato Cordeiro. João do Rio por Renato Cordeiro Gomes. Rio de Janeiro: Agir, 2005. (Coleção Nossos Clássicos).

SCHAPOCHNIK, Nelson. Cartões postais, álbuns de família e ícones da intimidade. In: SEVCENKO, Nicolau (Org.). História da vida privada no Brasil. São Paulo: Companhia das Letras, 2004. v. 3. cap. 6, p. 423-512.

SEVCENKO, Nicolau. A capital irradiante: técnica, ritmos e ritos do Rio. In: SEVCENKO, Nicolau (Org.). História da vida privada no Brasil. São Paulo: Companhia das Letras, 2004. v. 3. cap. 7, p. 513-620.

SODRÉ, Nelson Werneck. História da imprensa no Brasil. Rio de Janeiro: Mauad, 1999.

SUSSEKIND, Flora. Cinematógrafo de letras. Literatura, técnica e modernização no Brasil. São Paulo: Companhia das Letras, 2006.

VISCONTI, Eliseu. Esboço para cartaz. 1920 - 1 original colorido de pintura sobre papel - Obras Raras e Iconografia / Fundação Biblioteca Nacional. 